\title{
Dissimilar autogenous full penetration welding of superalloy K418 and 42CrMo steel by a high power CW Nd:YAG laser
}

\author{
Xiu-Bo Liu ${ }^{\text {a,b }}$, Gang Yu ${ }^{\text {a,*}}$, Ming Pang ${ }^{a}$, Ji-Wei Fan ${ }^{\mathrm{b}}$, Heng-Hai Wang ${ }^{\mathrm{a}}$, Cai-Yun Zheng ${ }^{\mathrm{a}}$ \\ ${ }^{\mathrm{a}}$ The Laboratory for Laser Intelligent Manufacturing, Institute of Mechanics, Chinese Academy of Sciences, 15 Beisihuanxi Road, \\ Beijing 100080, PR China \\ ${ }^{\mathrm{b}}$ School of Materials \& Chemical Engineering, Zhongyuan Institute of Technology, 41 Zhongyuan Western Road, \\ Zhengzhou 450007, Henan Province, PR China
}

Received 28 November 2006; received in revised form 5 March 2007; accepted 5 March 2007

Available online 12 March 2007

\begin{abstract}
Experiments of autogenous laser full penetration welding between dissimilar cast Ni-based superalloy K418 and alloy steel $42 \mathrm{CrMo}$ flat plates with $3.5 \mathrm{~mm}$ thickness were conducted using a $3 \mathrm{~kW}$ continuous wave $(\mathrm{CW}) \mathrm{Nd}$ :YAG laser. The influences of laser welding velocity, flow rate of side-blow shielding gas, defocusing distance were investigated. Microstructure of the welded seam was characterized by optical microscopy (OM), scanning electron microscopy (SEM) and X-ray diffraction (XRD) and energy dispersive spectrometer (EDS). Mechanical properties of the welded seam were evaluated by microhardness and tensile strength testing. Results show that high quality full penetration laser-welded joint can be obtained by optimizing the welding velocity, flow rate of shielding gas and defocusing distance. The laser-welded seam have non-equilibrium solidified microstructures consisting of $\gamma-\mathrm{FeCr}_{0.29} \mathrm{Ni}_{0.16} \mathrm{C}_{0.06}$ austenite solid solution dendrites as the dominant and very small amount of super-fine dispersed $\mathrm{Ni}_{3} \mathrm{Al} \gamma^{\prime}$ phase and Laves particles as well as MC needle-like carbides distributed in the interdendritic regions. Although the microhardness of the laser-welded seam was lower than that of the base metal, the strength of the joint was equal to that of the base metal and the fracture mechanism showed fine ductility.
\end{abstract}

(C) 2007 Elsevier B.V. All rights reserved.

Keywords: Laser processing; Metals and alloys; Full penetration welding; Microstructure; Mechanical properties

\section{Introduction}

The turbocompressor rotor is a key component of the engine and its quality has critical influences on the service life of the engine. It is usually fabricated in China by welding the Chinese K418 Ni-based cast superalloy turbo disk to the quenchtempered Chinese 42CrMo alloy steel shaft. Since the thermal physical and high-temperature mechanical properties of the above two materials are so different (see Tables 1 and 2), and the Ni-based superalloy has great susceptibility to cracking in the heat-affected zone (HAZ) during welding. Furthermore, carbon equivalent of the medium carbon $42 \mathrm{CrMo}$ alloy steel is about $0.834 \%$, which means it bears strong quenching harden tendency during welding process, and hence, rather poor welding ability. Therefore, their welding process belongs to the

\footnotetext{
* Corresponding author. Tel.: +86 106252 1859; fax: +86 1062521859 .

E-mail address: gyu@imech.ac.cn (G. Yu).
}

typically dissimilar materials welding and usually is considered to be a great challenge. At present, the welding methods of these two materials are either electronic-beam welding or friction welding. But the electronic-beam welding process needs vacuum chamber and produces harmful X-rays. On the other hand, the prospect of totally encompassing huge components in a vacuum canopy in order to effect the welding is not practicable. As for the friction welding, low stress destruction often occurred and welding defects are observed near the fusion zone usually and results in lower production efficiency. For a long time, failure of such joints has plagued Chinese turbocompressor makers $[1,2]$.

Laser welding is a high energy density, low heat-input process with specific advantages over conventional fusion welding processes. These include high welding speed, narrow heat-affected zone, low distortion, ease of automation, singlepass thick section capability and enhanced design flexibility. One of the many features of laser welding is the capability to weld without filler materials (autogenous welding) and it offers 
Table 1

Thermal-physical properties of $42 \mathrm{CrMo}$

\begin{tabular}{|c|c|c|c|c|c|c|c|c|c|c|c|c|}
\hline & \multicolumn{12}{|c|}{ Temperature $(\mathrm{K})$} \\
\hline & 293 & 373 & 473 & 573 & 673 & 773 & 873 & 973 & 1035 & 1073 & 1173 & 1273 \\
\hline$C_{p}(\mathrm{~J} /(\mathrm{kg} \mathrm{K}))$, specific heat & 470 & 484 & 521 & 560 & 607 & 668 & 745 & 873 & 1075 & 796 & 684 & 677 \\
\hline$K(\mathrm{~W} /(\mathrm{m} \mathrm{K}))$, coefficient of thermal conductivity & 39 & 36 & 35 & 34 & 33 & 31 & 29 & 25 & 20 & 21 & 24 & 23 \\
\hline
\end{tabular}

Table 2

Thermal-physical properties of K418

\begin{tabular}{|c|c|c|c|c|c|c|c|c|c|c|}
\hline & \multicolumn{10}{|c|}{ Temperature $(\mathrm{K})$} \\
\hline & 293 & 373 & 473 & 573 & 673 & 773 & 873 & 973 & 1073 & 1173 \\
\hline$C_{p}(\mathrm{~J} /(\mathrm{kg} \mathrm{K}))$, specific heat & 529 & 535 & 549 & 573 & 542 & 565 & 602 & 650 & 706 & 763 \\
\hline$K(\mathrm{~W} /(\mathrm{m} \mathrm{K}))$, coefficient of thermal conductivity & 9 & 10 & 12 & 13 & 14 & 16 & 18 & 21 & 24 & 28 \\
\hline
\end{tabular}

distinct advantages [3-7]. Laser welding has recently received growing attention due to its special features and potential. In terms of weldability for metallic materials, Nd:YAG laser has various advantages, such as a high energy absorption rate due to a low reflectivity, a high welding speed and a low residual stress compared to $\mathrm{CO}_{2}$ laser, so the application of Nd:YAG laser to weld metallic materials is steadily being increased, it has been widely implemented in industrial applications, e.g. in the automotive industry [8,9]. But presently, laser power levels are limited for the material thickness involved. However, many more applications could arise following further investigation. In this paper, an attempt was made to explore the possibility of welding the above two materials in $3.5 \mathrm{~mm}$ thickness by a high power CW Nd:YAG laser, technique parameters for acquiring a high quality full penetration welded joint, such as laser-welding velocity, flow rate of shielding gas, defocusing distance were optimized. Microhardness and tensile strength of the welded joint were also tested.

\section{Experimental details}

K418 Ni-based cast superalloy and the quench-tempered $42 \mathrm{CrMo}$ steel plates, with the thickness of $3.5 \mathrm{~mm}$, were put edge to edge. Tables 3 and 4 show the detail chemical compositions of these two materials. Before welding, any oxide layers and contamination were removed from the surfaces of the plates, especially the surfaces needed for welding were cleaned with acetone, ethanol and then dried. The accuracy requirement for the platform is very high during laser-welding process, the horizontal and vertical accuracies were adjusted through the micrometer and the error range was within $0.04 \mathrm{~mm}$. Flow of high purity argon gas was passed through the molten pool from both top and lateral sides to provide a protective environment for the sake of avoiding the reaction between the molten metals and ambient air.

Experiments of laser welding of the above two materials were conducted on a $3 \mathrm{~kW} \mathrm{CW}$ Nd:YAG laser materials processing systems with numerical control carries out the spacial displacement of the assembly without any filler metal. An oblique irradiation technique was adopted to overcome the problems of dissimilar materials to some extent. The employed parameters were optimized based on our previous experimental work, i.e., laser output power was kept constant as rated $3 \mathrm{~kW}$, laser beam scanning velocity varied between 15 and $35 \mathrm{~mm} / \mathrm{s}$, flow rate of side-blow shielding gas $5-20 \mathrm{l} / \mathrm{min}$ and the defocus distance -3 to $+2 \mathrm{~mm}$. The definition of defocus distance is positive when the focus point is above and negative when the focus point is beneath the surface of the work-piece. The aim of this design was to investigate the influences of each parameter on the weld quality when other parameters were kept constant and acquire the optimized parameters for high quality full

Table 3

Chemical composition of K418 (wt\%)

\begin{tabular}{ll}
\hline $\mathrm{C}$ & $0.08-0.16$ \\
$\mathrm{Cr}$ & $11.5-13.5$ \\
$\mathrm{Mo}$ & $3.8-4.8$ \\
$\mathrm{Nb}$ & $1.8-2.5$ \\
$\mathrm{Al}$ & $5.5-6.4$ \\
$\mathrm{Ti}$ & $0.5-1.0$ \\
$\mathrm{Zr}$ & $0.06-0.15$ \\
$\mathrm{~B}$ & $0.008-0.020$ \\
$\mathrm{Mn}$ & $\leq 0.50$ \\
$\mathrm{Si}$ & $\leq 0.50$ \\
$\mathrm{P}$ & $\leq 0.015$ \\
$\mathrm{~S}$ & $\leq 0.010$ \\
$\mathrm{Fe}$ & $\leq 1.0$ \\
$\mathrm{~Pb}$ & $\leq 0.001$ \\
$\mathrm{Bi}$ & $\leq 0.0001$ \\
$\mathrm{Ni}$ & Balance \\
\hline
\end{tabular}

Table 4

Chemical composition of 42CrMo (wt $\%$ )

\begin{tabular}{ll}
\hline $\mathrm{C}$ & $0.38-0.45$ \\
$\mathrm{Cr}$ & $0.90-1.20$ \\
$\mathrm{Mo}$ & $0.15-0.25$ \\
$\mathrm{Mn}$ & $0.50-0.80$ \\
$\mathrm{Si}$ & $0.20-0.40$ \\
$\mathrm{P}$ & $\leq 0.040$ \\
$\mathrm{~S}$ & $\leq 0.040$ \\
$\mathrm{Fe}$ & Balance \\
\hline
\end{tabular}




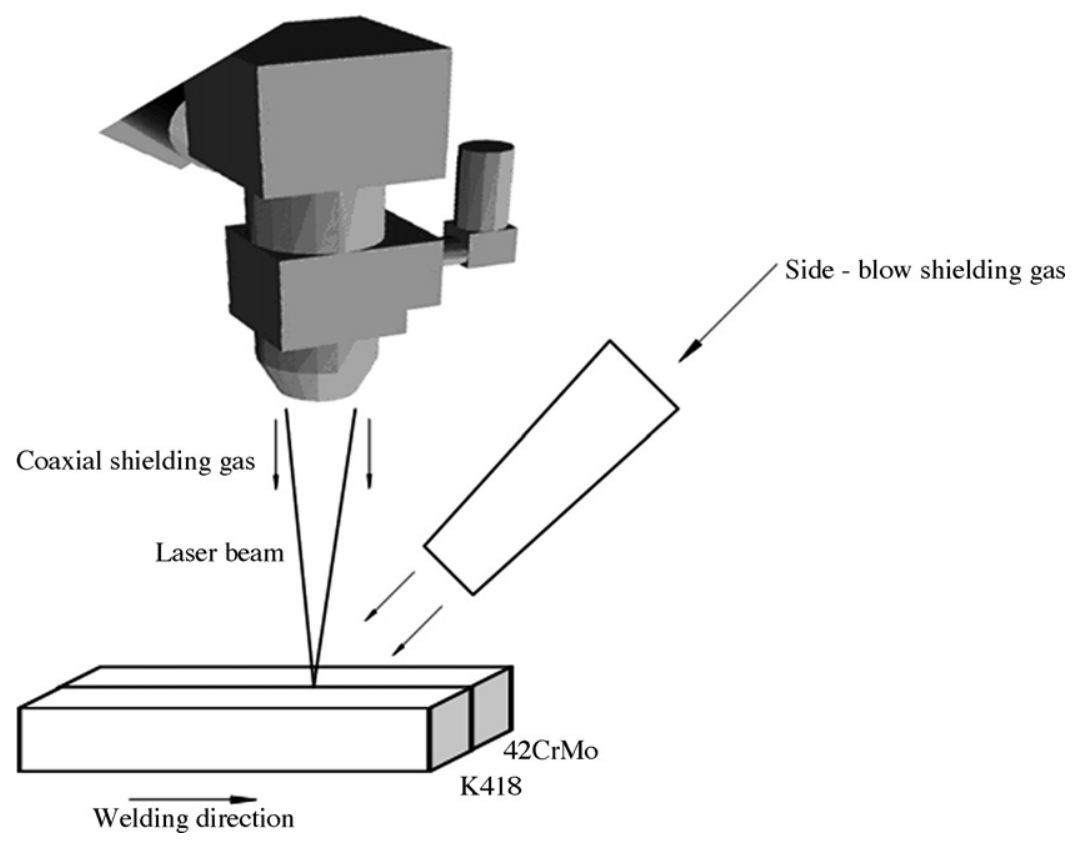

Fig. 1. Schematic diagram of the experimental set-up.

penetration welded joint. The whole laser-welding system was illustrated in Fig. 1. After welding, no post-weld heat treatments were performed.

Metallographic samples and tensile test specimens were machined by electric discharging cutting, followed by mechanical milling and grinding to acquire the testing surface with roughness of $0.8 \mu \mathrm{m}$ from the slight rough as-laser-welded specimens. Metallographic sample of the welded seam was prepared using standard mechanical polishing procedures and was etched in $\mathrm{HCl}: \mathrm{HNO}_{3}$ solution in volume ratio of $3: 1$. Microstructure of the welded seam was characterized by NephotII optical microscopy (OM), JSM-5800 scanning electron microscopy (SEM) equipped with LinkISIS S-530 energydispersive spectrometer (EDS). A D/max-rB high power multicrystal X-ray diffractometer (XRD) was used for phase identification. The recorded intensities and peak positions were compared with Joint Committee on Powder Diffraction Standards (JCPDS) data. The microhardness along the transverse direction of the welded joint was measured by an automatic microhardness tester (HXD-1000B, Shanghai Optics Apparatus Ltd., China) with a testing load of $1.96 \mathrm{~N}$ and a dwelling time of $15 \mathrm{~s}$. The values of hardness were averaged by at least five points of measurements. The transverse tensile test was conducted with a universal testing machine at a cross-head speed of $2 \mathrm{~mm} / \mathrm{min}$ to evaluate the tensile strength of the joints. The breaking force (Bf: N) was recorded when the specimen fractured, after tensile test, the fracture surface was observed using a scanning electron microscope (SEM) to correlate with the type of fracture.

\section{Results and discussion}

\subsection{Morphology of the welded seam}

The power density available from a laser beam spans many orders of magnitude and can attain approximately $10^{8} \mathrm{~W} \mathrm{~cm}^{-2}$.
A power density below approximately $10^{6} \mathrm{~W} \mathrm{~cm}^{-2}$ allows welding to be performed in the thermal-conductive mode. The beam energy is deposited on the material surface, transferred into the material by conduction, and a hemispherical weld bead is formed in a similar manner to conventional fusion welding processes. In contrast, when the laser energy density exceeds a certain limit (usually $10^{6}$ to $5 \times 10^{7} \mathrm{~W} \mathrm{~cm}^{-2}$ ) to initiate local vaporization, the reaction force of the evaporated metal gas increased rapidly. Vibration and deformation of the liquid surface became large due to the increased vapor pressure. Then a keyhole was formed in the molten pool, and the material was heated directly by the laser beam through the keyhole. Thus deep penetration welding by the keyhole mode was achieved $[10,11]$. Experimental observation showed that the morphology of the cross-sections of the welded seams was asymmetric, and exhibited $\mathrm{X}$ shape and $\mathrm{T}$ shape according to the various welding parameters, as can be seen clearly in Fig. 2. The asymmetric degree in the bottom region was more serious than that of the upper region, which indicated its more uneven of the molten metal's flowing and thermal conductivity [12]. The left side of the welded seam was 42CrMo and the right side was $\mathrm{K} 418$. We defined the laser output power as $P$, welding velocity as $v$, sideblow shielding gas flow rate as $U_{\mathrm{f}}$, defocus distance as $\Delta Z$, the cap width as $W_{\mathrm{u}}$, the root width as $W_{\mathrm{b}}$, the width of the straight and flat region in the central region of the seam as $W_{\mathrm{m}}$, the upper and under arc height near 42CrMo as $H_{\mathrm{u} 1}$ and $H_{\mathrm{b} 1}$, the upper and under arc height near $\mathrm{K} 418$ as $H_{\mathrm{u} 2}$ and $H_{\mathrm{b} 2}$, respectively, as clearly indicated in Fig. 3.

\subsection{Influence of welding velocity}

As could be seen in Fig. 4, when the welding velocity was within the low range, shallow concave shape existed in the cap region and remnant metal droplet left at the root region and inclined to the K418 alloy side, which possesses the lower 

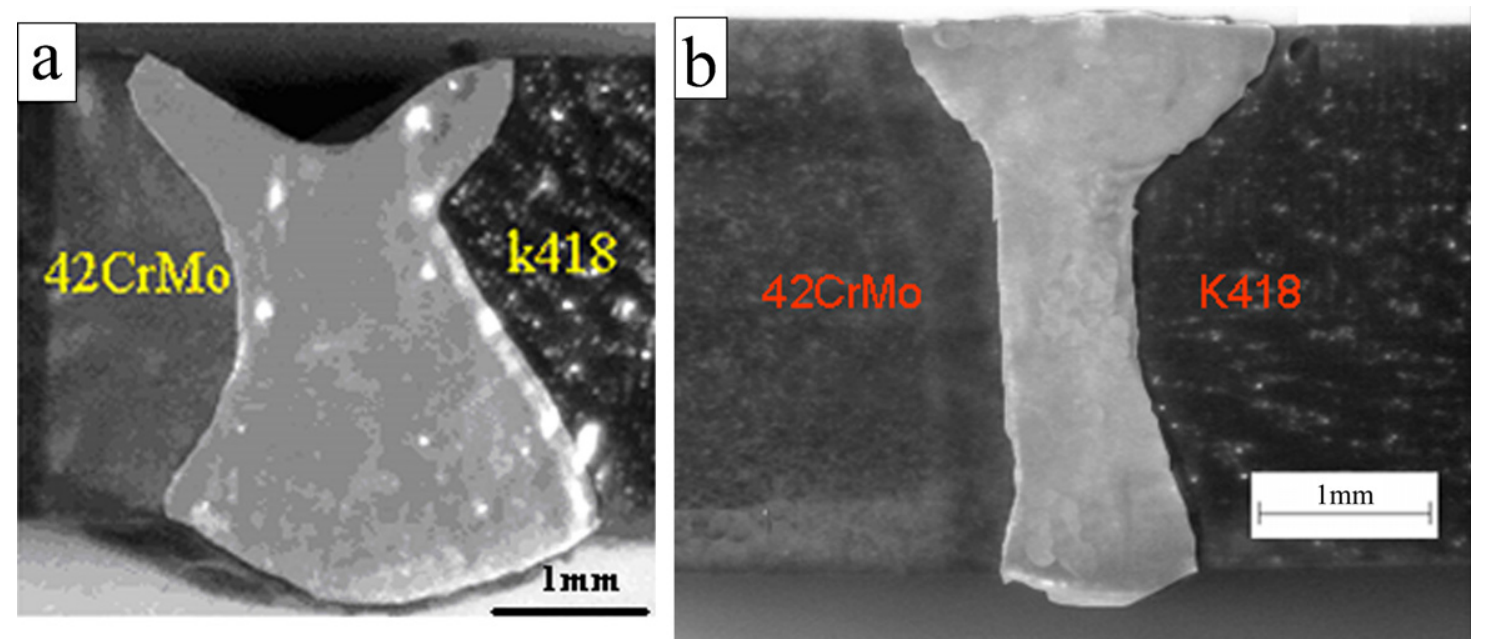

Fig. 2. Cross-section of K418 and 42CrMo laser full penetration welded seam: (a) $P=3 \mathrm{~kW}, v=15 \mathrm{~mm} / \mathrm{s}, \Delta Z=0, U_{\mathrm{f}}=5 \mathrm{l} / \mathrm{min}$ and (b) $P=3 \mathrm{~kW}, v=35 \mathrm{~mm} / \mathrm{s}$, $\Delta Z=+1 \mathrm{~mm}, U_{\mathrm{f}}=15 \mathrm{l} / \mathrm{min}$.

thermal conductivity coefficient. The root width $\left(W_{\mathrm{b}}\right)$ was larger than that of the cap $\left(W_{\mathrm{u}}\right)$, this phenomenon is mainly attributed to the fact that the actual laser scanning speed is relatively slow and much more metals have been melted during the laser direct radiation, thus the shape of the molten pool is dominated by the gravity of the melted liquid metal rather than the molten pool's surface tension, and the whole melt pool shows the concave tendency along the depth direction, so more neighboring base metal at the root region than the cap region could be melted through laser radiation and subsequent thermal conduction. With the increasing of the welding velocity, the

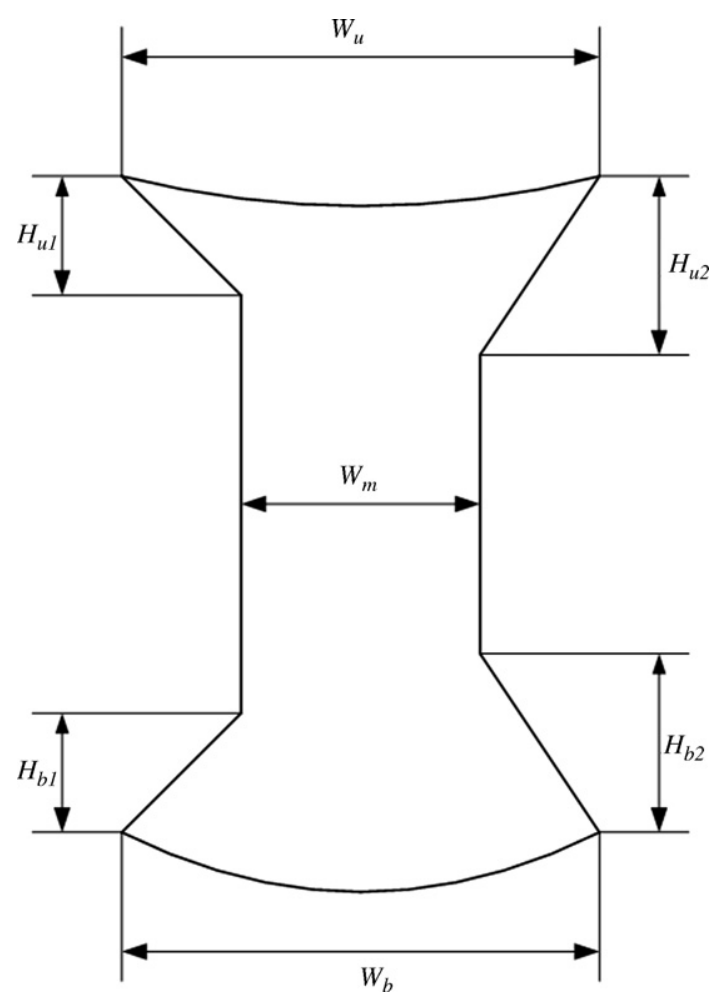

Fig. 3. Schematic representation of cross-section region dimension of the welded seam. dimension of the welded seam became small and the change was more serious in the bottom than that in the upper region, the morphology of the welded seam gradually changed from $\mathrm{X}$ shape to $\mathrm{T}$ shape. This is due to the metal vapor and plasma generated in the deep penetration laser-welding process were ejected along the up and bottom side of the keyhole, and then exerted their action on the cap and root side of the welded seam as a heat source, the liquid metal at the wall of the keyhole melts the surrounding metal through thermal conduction, the laser beam penetrated the keyhole could heat the metal vapor and plasma plume at the root side of the welded seam. The basic principal of the process could be consulted from Ref. [13]. With the increasing of the welding velocity, the amount of melted and vaporized metal was decreasing and hence, the decreased density of the metal vapor and plasma ejected from the keyhole, the thermal conduction time of the liquid metal to the surrounding metal was less, so the less interaction time of the laser beam to the metal vapor and plasma plume on the cap and root side of the welded seam, thus the dimension of the welded seam was decreasing with the increasing welding velocity. Because of the synthesizing influences of the coaxial and sideblow shielding gas and the laser source on the cap side, the dimension of the bottom region changed more violently than that of the upper region of the welded seam. When the welding velocity decreased to $15 \mathrm{~mm} / \mathrm{s}$, serious concave appeared on the surface of the welded seam and this phenomenon was alleviated with the increase of welding velocity.

\subsection{Influence of flow rate of side-blow shielding gas}

As indicated in Fig. 5, it could be seen that the influences of the flow rate of side-blow shielding gas on the quality and dimension of the welded seam was very complicated and depended on the integrated effects of the plasma. The width of the cap and root side of the welded seam $\left(W_{\mathrm{u}}\right.$ and $\left.W_{\mathrm{b}}\right)$ increased first and then, decreased and increased again with the increasing flow-rate of the side-blow shielding gas. The width of the straight and flat region in the central region of the welded seam 

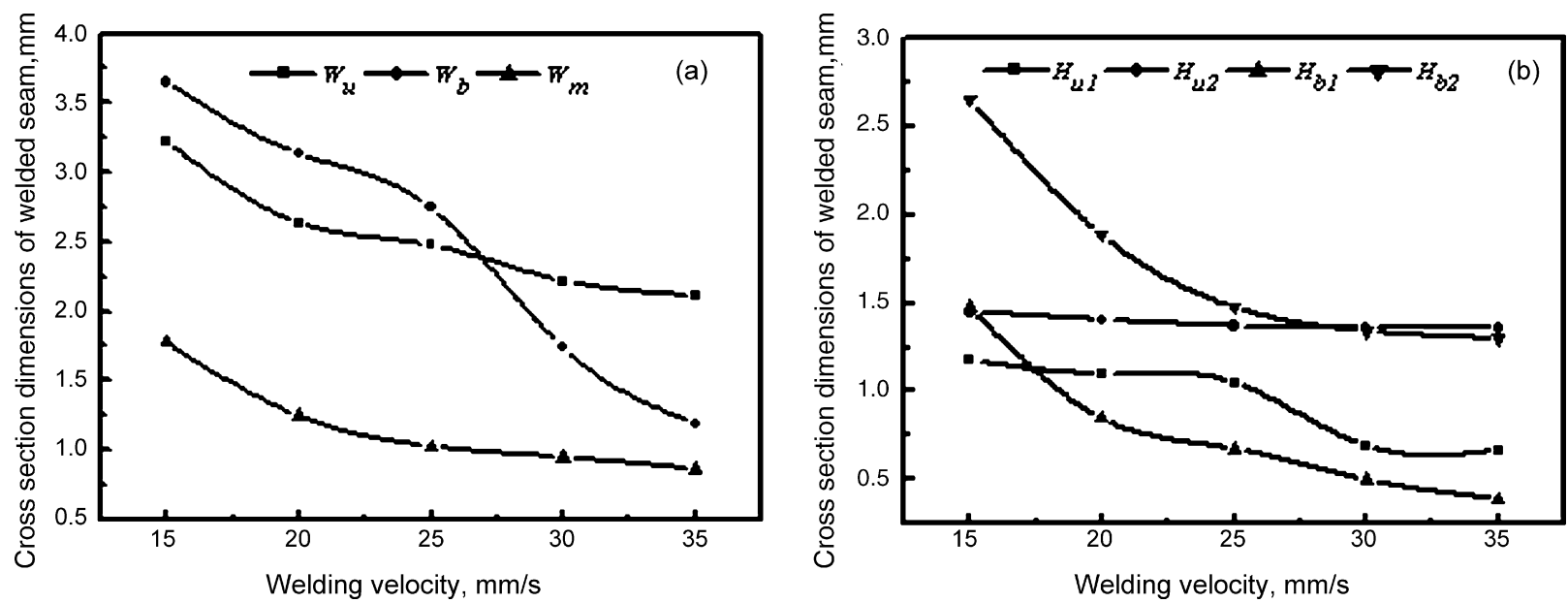

Fig. 4. Influences of laser-welding velocity on cross-section region dimension of the welded seam: $P=3 \mathrm{~kW}, \Delta Z=0, U_{\mathrm{f}}=15 \mathrm{l} / \mathrm{min}$.

$\left(W_{\mathrm{m}}\right)$ decreased first and then, increased with the increasing flow-rate of the side-blow shielding gas. The variation of the width of the cap side was due to the fact that on one hand, the side-blow shielding gas had the ability to enlarge the molten pool with the increasing flow-rate of the side-blow shielding gas, on the other hand, the decreased plasma on the cap side could decrease the molten pool. The final result was the balance of these two factors [14]. The dimension variation of the straight and flat region in the central region of the welded seam $\left(W_{\mathrm{m}}\right)$ was the synthesizing effects of the cooling effects, and partial plasma plume was dispelled into the keyhole by the sideblow shielding gas. The change of the root side dimension was dominated by the integrated actions of the dropping liquid metal along the keyhole and the downwards ejected plasma and metal vapor. As could be seen in Fig. 5, the influence of the side-blow shielding gas was greater for $H_{\mathrm{u} 2}$ than that for $H_{\mathrm{b} 2}$, while more influence for $H_{\mathrm{b} 1}$ than $H_{\mathrm{u} 1}$. By observing the surface of the welded seam, concave hollow existed on the cap side when the flow rate of the side-blow shielding gas attained 5, 10 and $20 \mathrm{l} / \mathrm{min}$, respectively. While slight minor convex shape accompanied the flow rate of $15 \mathrm{l} / \mathrm{min}$.

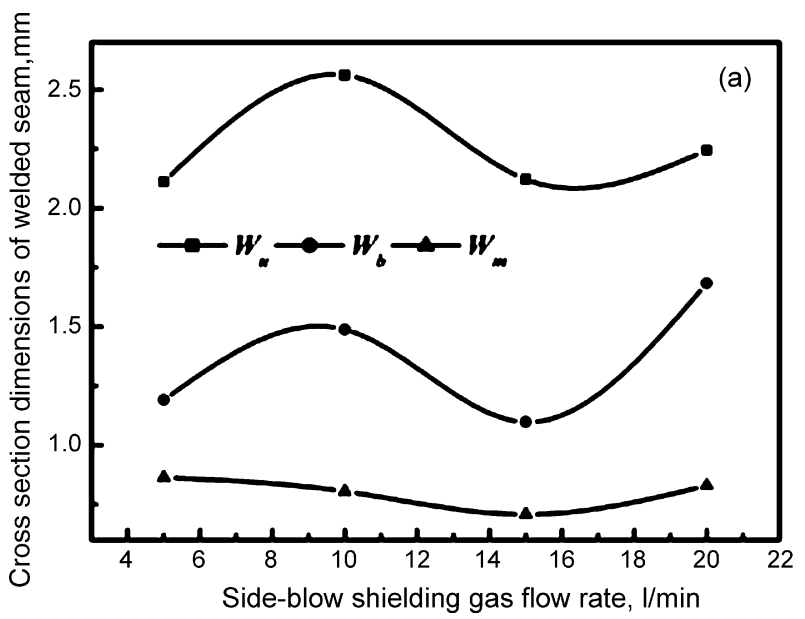

\subsection{Influence of defocus distance}

The power density exerted on the work-piece depends on both the laser beam's power density and the relative distance between the surface of the work-piece and the focus plane. Of course, different defocus distance represents different internal power density that exerted on the work-piece by laser. As shown in Fig. 6, the width of the cap side of the welded seam $\left(W_{\mathrm{u}}\right)$ decreased rapidly when the defocus distance changed from -3 to $-2 \mathrm{~mm}$, while negligible changes observed when the defocus distance changed from -2 to $1 \mathrm{~mm}$, and $W_{\mathrm{u}}$ increased swiftly when $\Delta Z$ changed from 1 to $2 \mathrm{~mm}$. Meanwhile, little variations could be seen in $W_{\mathrm{b}}$ and $W_{\mathrm{m}}$ when $\Delta Z$ changed from -3 to $2 \mathrm{~mm}$. The variation of $H_{\mathrm{b} 1}$ and $H_{\mathrm{b} 2}$ was more pronounced than $H_{\mathrm{u} 1}$ and $H_{\mathrm{u} 2}$ as a function of the defocus distance during the range of -3 to $+2 \mathrm{~mm}$. The fact that the variation of $W_{\mathrm{u}}$ is not symmetrical about the focus point is mainly due to that the laser focus point offset downwards about $0.5 \mathrm{~mm}$ under the action of thermal lens effects and the plasma second focusing effects during the welding process [15]. From the practical samples, it could be seen that the best

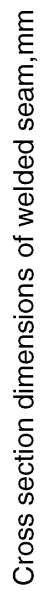

Fig. 5. Influences of side-blow shielding gas flow rate on cross-section region dimension of welded seam: $P=3 \mathrm{~kW}, \Delta Z=0, v=35 \mathrm{~mm} / \mathrm{s}$. 

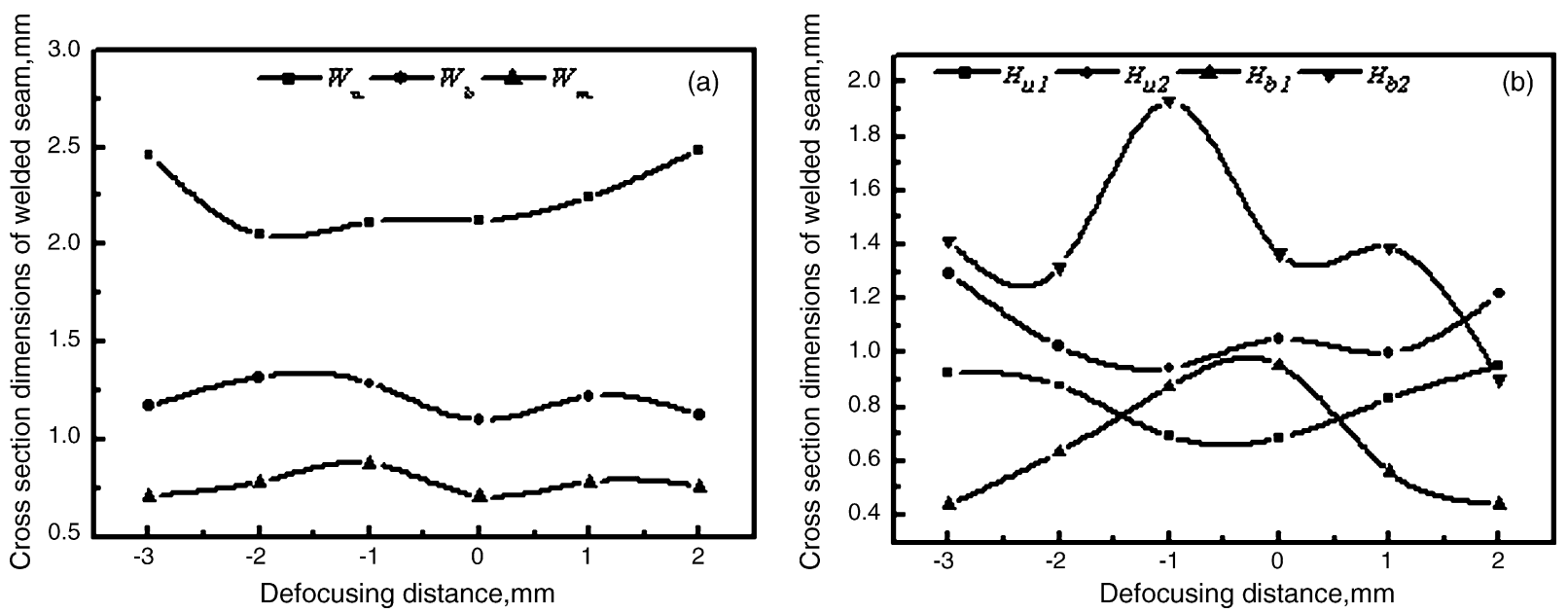

Fig. 6. Influences of defocusing distance on cross-section region dimension of the welded seam: $P=3 \mathrm{~kW}, U_{\mathrm{f}}=151 / \mathrm{min}, v=35 \mathrm{~mm} / \mathrm{s}$.
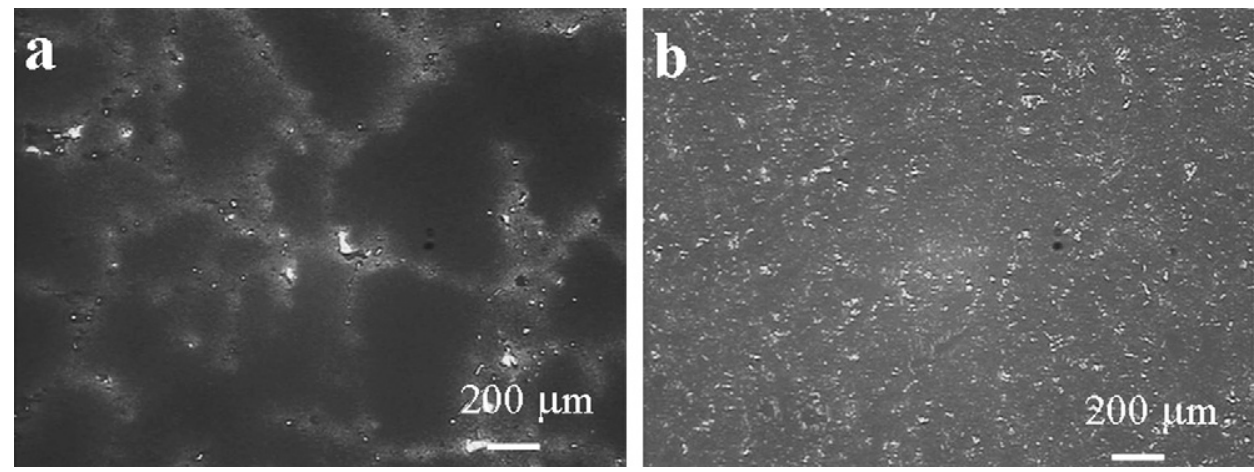

Fig. 7. OM micrographs showing the as-received base metal: (a) K418 and (b) 42CrMo.

macro-morphology quality was achieved under the positive defocus distance of $+1 \mathrm{~mm}$.

\subsection{Microstructure examinations}

The OM micrographs of the as-received base metal K418 and 42CrMo metal are shown in Fig. 7(a) and (b), respectively. It can be seen that the microstructure of the as-received K418 superalloy possesses rather coarse (about $2 \mathrm{~mm}$ ) cast microstructure feature consisting of $\gamma$ matrix, dispersed $\mathrm{Ni}_{3} \mathrm{Al} \gamma^{\prime}$ precipitate particles isolated in the $\gamma$ matrix and very small amount of MC carbides and $\left(\gamma+\gamma^{\prime}\right)$ eutectics. While the asreceived $42 \mathrm{CrMo}$ steel mainly consists of tempered sorbite and needle-like ferrite. Fig. 8 demonstrates the X-ray diffraction results of the welded seam, from which it can be found that in the central region of the welded seam, the peaks of $\mathrm{FeCr}_{0.29}$ $\mathrm{Ni}_{0.16} \mathrm{C}_{0.06}$ are quite evident, which manifests the most amount of its content. Besides, small amount of $\mathrm{Ni}_{3} \mathrm{Al} \gamma^{\prime}$ intermetallics and $\mathrm{NbC}, \mathrm{TiC}$ type $\mathrm{MC}$ carbides could also be found. At SEM high magnifications, it can be seen from Fig. 9(a) and more clearly in Fig. 9 (b), except the main dendrite structure, minor super-fine bright etching irregular-shaped particles were observed in the interdendritic regions. The EDS analysis results obtained on the welded seam is shown in Table 5, which indicates that the dendrites are highly enriched in $\mathrm{Ni}, \mathrm{Fe}$ and $\mathrm{Cr}$, considering that the equipment cannot detect the composition of $\mathrm{C}$, so it supported the $\mathrm{XRD}$ results that the dominant dendrite is $\mathrm{FeCr}_{0.29} \mathrm{Ni}_{0.16} \mathrm{C}_{0.06}$ austenite solid solution. Meanwhile, the EDS results show that the fine particles are enriched in $\mathrm{Nb}$, Mo and $\mathrm{Ti}$ and lean in $\mathrm{Ni}, \mathrm{Cr}$ and $\mathrm{Fe}$ as compared to the solid solution dendrites matrix. Chemical composition of the particles enriched in $\mathrm{Nb}$ were identified as $(\mathrm{Fe}+\mathrm{Cr}+\mathrm{Ni}, \quad 70 \mathrm{wt} \%)$ and $(\mathrm{Ti}+\mathrm{Nb}+\mathrm{Mo}$, $28 \mathrm{wt} \%$ ). Considering their very small particle size, electron

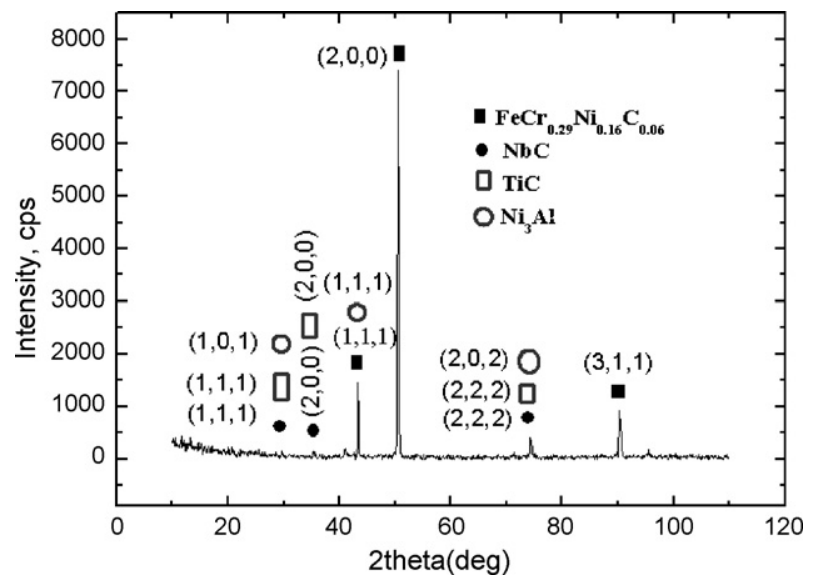

Fig. 8. XRD analysis results of the laser-welded seam. 

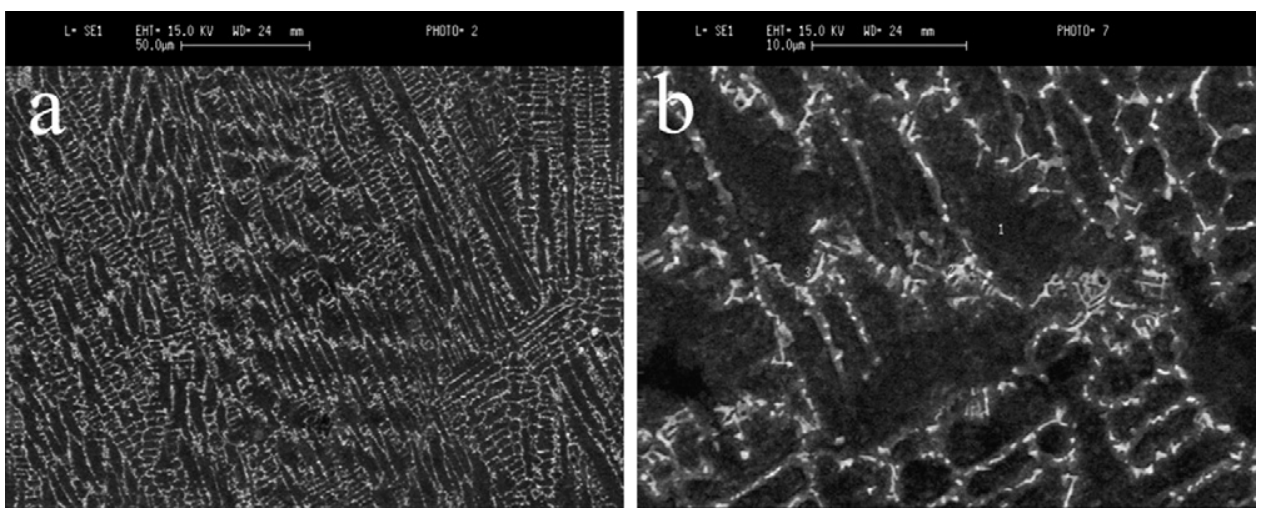

Fig. 9. Typical microstructure of the laser-welded seam: (a) SEM photograph showing the non-equilibrium solidified Ni solid solution dendrites and the fine dispersed particles distributed in the interdendritic regions (b) high magnification of (a)

probe microanalysis has a spot size of approximately one micrometer, which is larger than or equal to the particles size, resulting in the incorporation of the matrix materials. Synthesizing the above results, it is reasonable to deduce that the particles detected in the interdendritic regions were Laves phase, which is a hexagonally close packed phase and is generally accepted to be of the form $(\mathrm{Ni}, \mathrm{Cr}, \mathrm{Fe})_{2}(\mathrm{Nb}, \mathrm{Mo}, \mathrm{Ti})$. The results of Radhakrishna and Rao [16] also mentioned that the formation of Laves phase requires a niobium concentration ranging from 10 to $30 \%$, and segregation is a prerequisite for the initiation of Laves phase, and segregation is a timedependent phenomenon and hence is strongly affected by the welding cooling rate, as influenced by various factors like heat input, welding process, etc. Slow weld cooling rates result in relatively large dendritic arm spacings compared to rapidly cooled welds, and these coarse dendritic spacings provide congenial/preferential sites for segregation of alloying elements during weld solidification. Recently, Janaki Ram et al. [17] mentioned the presence of some amount of Nb-rich brittle intermetallic Laves phase in fusion zone microstructure during the pulsed Nd-YAG laser welding of Inconel 718 alloy and the attendant inferior mechanical properties in relation to the base metal, due to the employed relatively slow welding speed and the resultant relatively slow cooled welds. As well known, the formation of Laves phase, particularly in solidified structures is detrimental and hence, warrants careful control. Because of the rapidly cooled welds employed in this instance, only very small amount of dispersed particles, i.e. Laves phase, were formed. Due to their very small amount and relatively uniform distribution in the interdendritic regions, no deleterious effects on mechanical properties would be expected. Minor needlelike phases isolated in the interdendritic regions, as shown in

Table 5

EDS analysis results of the laser-welded seam (wt $\%$ )

\begin{tabular}{llllllll}
\hline & \multicolumn{2}{l}{ Major elements } & & & & & \\
\cline { 2 - 8 } & $\mathrm{Ni}$ & $\mathrm{Fe}$ & $\mathrm{Cr}$ & $\mathrm{Mo}$ & $\mathrm{Al}$ & \multicolumn{1}{c}{$\mathrm{Nb}$} & $\mathrm{Ti}$ \\
\hline Dendrites & 52.45 & 36.49 & 7.14 & 0.70 & 1.42 & 1.56 & 0.24 \\
Particles & 36.85 & 26.10 & 7.91 & 4.27 & 1.32 & 17.39 & 6.16 \\
Needles & 46.35 & 30.21 & 7.13 & 2.01 & 1.45 & 10.02 & 2.83 \\
\hline
\end{tabular}

Fig. 9(b), are detected by EDS as enriched in Ti and $\mathrm{Nb}$ and confirmed as MC type carbides on account of the combined reasons of XRD results and strong affinity of $\mathrm{Ti}$ and $\mathrm{Nb}$ with $\mathrm{C}$ in the melted pool. It is hard to exactly identify and clearly marked the $\mathrm{Ni}_{3} \mathrm{Al} \gamma^{\prime}$ phase due to the small amount and the superposed distribution with Laves phase and MC carbides although the XRD results indicate its existence.

\subsection{The microhardness and transverse tensile tests}

Fig. 10 exhibited the microhardness test results of the laserwelded joint. It could be seen that the microhardness of the welded seam was the lowest and, averaged about at HV233. While microhardness of the HAZ of the K418 was about 389 , and then, quickly changed to the base metal, i.e. about HV 375. The microhardness of the HAZ of the $42 \mathrm{CrMo}$ was the highest, ranged between HV518 and HV643 and then gradually transferred to the base metal, about HV356.

The hardness of the welded seam was the lowest owing to the partial dissolution of the strengthening phase $\mathrm{Ni}_{3} \mathrm{Al} \gamma^{\prime}$ and the subsequent rapid solidification inherent to laser processing could suppress the formation of the phase $\mathrm{Ni}_{3} \mathrm{Al} \gamma^{\prime}$ to some extent [18]. Also, the alloy elements coming from the $42 \mathrm{CrMo}$ could result some dilution effects of the molten pool.

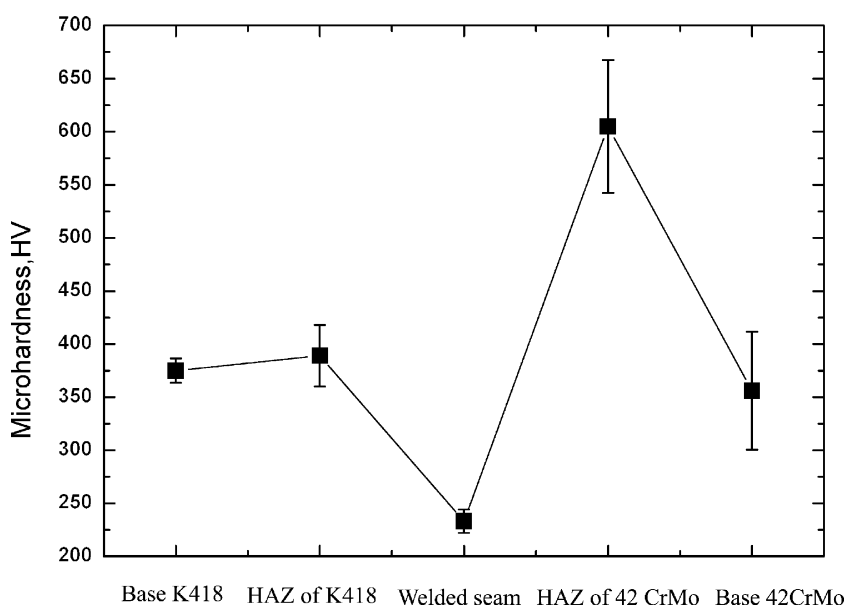

Fig. 10. Microhardness distribution profile of the laser-welded joint. 

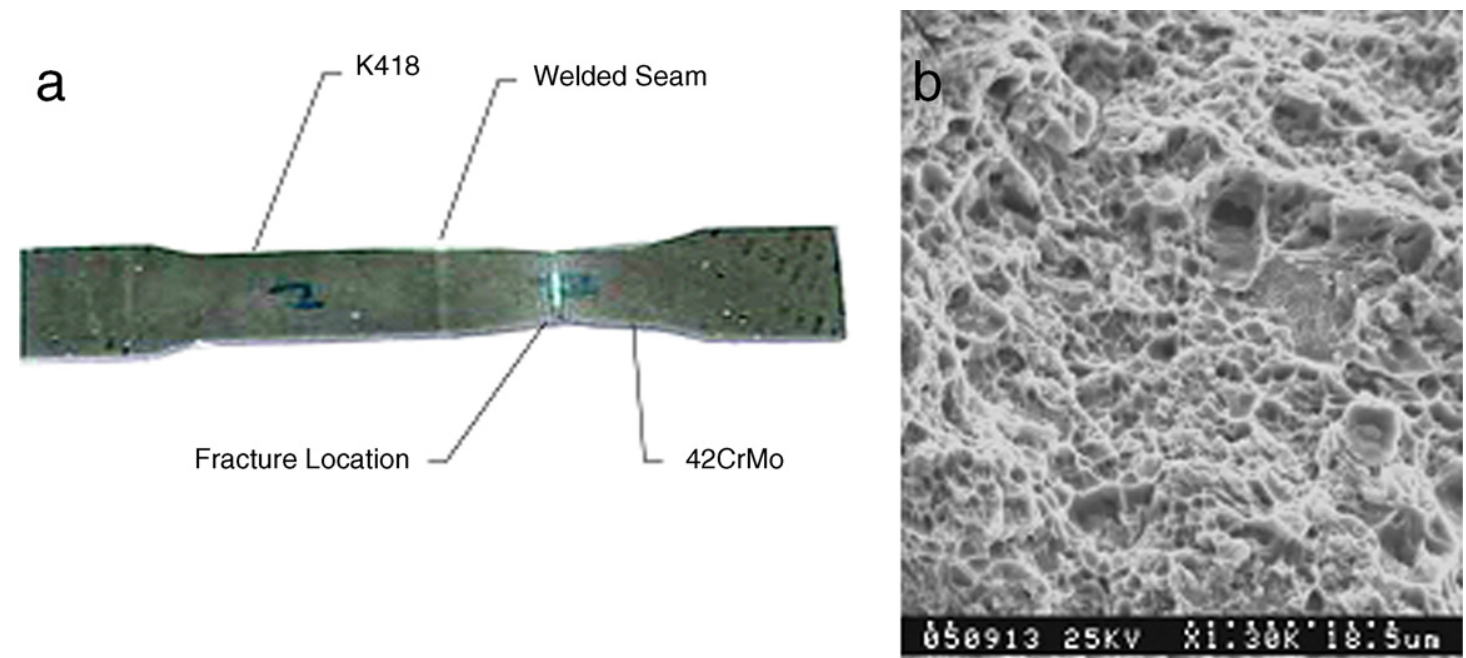

Fig. 11. Location of fracture during transverse tensile test (a) and SEM image showing the tensile fracture surface of the base alloy steel $42 \mathrm{CrMo}$ (b).

The reason why the hardness of the $42 \mathrm{CrMo} \mathrm{HAZ}$ was the highest is due to the self-quenching effects and the formation of a large amount of martensite. There were a few points show the serious microhardness fluctuation in the Base $42 \mathrm{CrMo}$ and $\mathrm{HAZ}$ of $42 \mathrm{CrMo}$ due to the heterogeneous microstructure of the measured region as well as measurement errors, but the values of hardness were averaged by at least five points of measurements, so the hardness result was relatively reasonable and acceptable.

The results of the joint transverse tensile test showed that the joint fractured in the $42 \mathrm{CrMo}$ base metal, outside the welded seam (Fig. 11a). The strength of the joint was at least equal to or larger than that of the alternative base metal, and the fracture mechanism showed fine ductility. The base material 42CrMo's fracture surface exhibited predominately dimpled rupture features without any preferentially fracture path (Fig. 11b). It is worthy note that there is relationship between the hardness and strength of steels, where normally the hardness increases while the strength increases, and the ductility decreases. But in this study, on the one hand, the microstructure of the welded seam was significantly refined due to the laser beam welding induced non-equilibrium rapid solidification and, hence, increased its strength. On the other hand, partial dissolution of the strengthening phase $\mathrm{Ni}_{3} \mathrm{Al} \gamma^{\prime}$ and the alloy elements coming from the 42CrMo could result some dilution effects of the fusion zone. Under this condition, the paper shows that the non-equilibrium rapid solidification inherent to laser processing has a strong effect. During their research of microstructures and mechanical properties of Ti$24 \mathrm{Al}-17 \mathrm{Nb}$ (at.\%) laser beam welding joints, Wu et al. [19] also mentioned that compared to the base metal, laser-welded metal was difficult to deform during tension, owing to its solidification fine dendritic structure. The deformation concentrated on the base metal and the fracture occurred in the base metal. As a result, the tensile strength of the joints was equal to that of the base metal. Wu's results were consistent with our results on the whole and corroborated our above analysis and deduction to some extent.

\section{Conclusions}

$\mathrm{X}$ and $\mathrm{T}$ shape welded seam morphologies were observed in the dissimilar autogenous full penetration laser welding of superalloy $\mathrm{K} 418$ and 42CrMo steel. Asymmetrical welded seam cross-section was acquired due to their different thermal physical properties, such as melting point, coefficient of thermal conduction and the flow ability of the liquid metal. The quality of the welded seam could be improved by appropriately increasing the welding velocity and adjusting the flow rate of the side-blow shielding gas. For the laser full penetration welding of dissimilar K418 and 42CrMo materials with $3.5 \mathrm{~mm}$ thickness under the rated power of $3 \mathrm{~kW}$ and the opposite sideblow shielding gas angle of $35^{\circ}$, the optimized welding parameters were as follows: welding velocity $35 \mathrm{~mm} / \mathrm{s}$, flow rate of side-blow shielding gas $15 \mathrm{l} / \mathrm{min}$ and positive defocus distance $+1 \mathrm{~mm}$. Microstructure of the laser-welded seam is mainly composed of $\mathrm{FeC}_{\mathrm{r} 0.29} \mathrm{Ni}_{0.16} \mathrm{C}_{0.06}$ austenite solid solution dendrites, very small amount of fine and dispersed Laves particles and MC carbides distributed in the interdendritic region. The microhardness of the laser-welded seam is lower than the base metal, but the strength of the joint was equal to that of the base metal and the fracture mechanism showed fine ductility. These results give useful indications for the development of an innovative laser-welding technique for the Ni-based cast superalloy K418 and alloy steel $42 \mathrm{CrMo}$. Further work about the welding of these two materials with more thickness and the practical components is strongly and urgently recommended. This is currently underway in our laboratory in this respect.

\section{Acknowledgements}

The authors are grateful for the financial support from the China Postdoctoral Science Foundation (Grant Number: 20060400105) and the Nature Science Research Program of Educational Ministry of Henan Province (Grant Number 2006430017). The invaluable assistance of Dr. Hong-Wei 
Song, senior engineer Wei-Jian Ning and engineer Li-Xin Wang of the Laboratory for Laser Intelligent Manufacturing, Institute of Mechanics, Chinese Academy of Sciences, during the laser-welding experiments, was gratefully acknowledged. The authors are also wish to thank the reviewers for their constructive suggestions and comments.

\section{References}

[1] S.G. Du, L. Fu, J.W. Wang, Y. Cao, Chin. J. Nonferr. Met. 13 (2) (2003) 323-327 (in Chinese).

[2] S.G. Du, L. Fu, Y. Cao, J.W. Wang, J. North Polytech. Univ. 22 (1) (2004) 112-115 (in Chinese).

[3] Z. Sun, J.C. Ion, J. Mater. Sci. 30 (1995) 4205-4214.

[4] Z. Sun, M. Kuo, J. Mater. Process. Technol. 87 (1999) 213-222.

[5] G. Yu, H.J. Yu, Integrated Laser Intelligent Manufacturing, Metallurgy Industry Press, Beijing, 2002.

[6] A. Sanderson, C.S. Punshon, J.D. Russell, Fus. Eng. Des. $49 / 50$ (2000) $77-$ 87.
[7] T.A. Mai, A.C. Spowage, Mater. Sci. Eng. A 374 (2004) 224-233.

[8] A. Ribolla, G.L. Damoulis, G.F. Batalha, J. Mater. Process. Technol. 164/ 165 (2005) 1120-1127.

[9] T.Y. Kuo, H.C. Lin, Mater. Sci. Eng. A 416 (2006) 281-289.

[10] Y.-T. Yoo, D.-G. Ahn, K.-B. Ro, S.-W. Song, H.-J. Shin, K. Im, J. Mater. Sci. 39 (2004) 6117-6119.

[11] R. Fabbro, S. Slimani, F. Coste, F. Briand, J. Phys. D: Appl. Phys. 38 (2005) 1881-1887.

[12] Abel-Monem, Ei-Batahgy, Mater. Lett. 32 (2/3) (1997) 155-163.

[13] W. Yao, S.L. Gong, L. Chen, Trans. Chin. Weld. Inst. 25 (5) (2004) 74-77 (in Chinese).

[14] T. Sibillano, A. Ancona, V. Berardi, E. Schingaro, G. Basile, P.M. Lugara, Opt. Lasers Eng. 44 (2006) 1039-1051.

[15] G.L. Qin, S.Y. Lin, Chin. J. Lasers 32 (4) (2005) 557-561 (in Chinese).

[16] Ch. Radhakrishna, K.P. Rao, J. Mater. Sci. 32 (1997) 1977-1984.

[17] G.D. Janaki Ram, A. Venugopal Reddy, K. Prasad Rao, G.M. Reddy, J.K. Sarin Sundar, J. Mater. Process. Technol. 167 (2005) 73-82.

[18] O.A. Ojo, M.C. Chaturvedi, Mater. Sci. Eng. A 403 (2005) 77-86.

[19] A.P. Wu, G.S. Zou, J.L. Ren, H.J. Zhang, G.Q. Wang, X. Liu, M.R. Xie, Intermetallics 10 (2002) 647-652. 